\title{
Os efeitos do crescimento econômico na pobreza do Ceará: uma análise microrregional
}

\author{
Lilian Lopes Ribeiro* \\ Débora Gaspar Feitosa** \\ Jair Andrade Araújo $0^{\star \star *}$
}

Resumo: Este artigo analisa se o crescimento econômico no estado do Ceará, desagregado em nível microrregional, tem sido pró-pobre em suas áreas urbanas e rurais. Ou seja, se a renda dos pobres tem apresentado uma elevação superior ao verificado pela renda dos não pobres, induzindo, assim, uma redução na desigualdade. Nesse sentido, com base nos dados do Censo dos anos de 2000 e 2010, são construídas as curvas de crescimento-pobreza, proposta por Son (2004). Os resultados obtidos apontaram que apenas 14 das 33 microrregiões do estado apresentam crescimento pró-pobre. Quando as microrregiões são desagregadas em área urbana e rural, verificou-se que 23 microrregiões apresentam crescimento em favor dos pobres nas áreas urbanas e somente quatro experimentam essa modalidade de crescimento na área rural. Nota-se, então, que o crescimento econômico do Ceará é pouco eficaz no combate à pobreza, principalmente no meio rural.

Palavras-chave: Crescimento pró-pobre. Pobreza. Desigualdade.

Classificação JEL: I32.

\section{Introdução}

Nestes últimos anos, a literatura na área de pobreza tem sido contemplada também por estudos multidimensionais sobre o tema, considerando não somente indicadores monetários, como também indicadores de saúde, educação, dentre outras dimensões. Apesar disso, definir e estudar a pobreza a partir da privação de renda é e provavelmente continuará sendo a base principal para definir quem é pobre.

Sen (2001), apesar de defender a utilização de indicadores não monetários para mensurar a pobreza, reconhece a importância da utilização da variável renda em comparação a outros indicadores. Segundo o autor, sua maior importância repousa principalmente na sua capacidade de comparação inter-regional e temporal, dada a sua ampla utilização. Nesse sentido, uma literatura amplamente utilizada é a de crescimento pró-pobre, que tem como premissa analisar os efeitos do crescimento econômico na pobreza de uma dada sociedade.

\footnotetext{
*Universidade Federal do Ceará - Campus Sobral. E-mail: liadiniz-21@hotmail.com

** Professora e pesquisadora da UFC/Sobral. E-mail: deborag@hotmail.com

*** Professor da Universidade Federal do Ceará. E-mail: jaira@hotmail.com
} 
O estudo da relação entre crescimento e pobreza surgiu de evidências empíricas segundo as quais nem sempre o crescimento resulta em uma melhora nos indicadores de pobreza. Ao contrário, estudos mostram que o crescimento de algumas nações em desenvolvimento vem acompanhado de uma piora nos níveis de pobreza e bem-estar. Trabalhos como o de Ahluwalia et al. (1979) vão nessa direção.

Dados do IPEA (2010) apontam que, entre os anos de 2003 e 2009, o estado do Ceará acumulou um crescimento de 28,1\%, percentual superior ao da média brasileira, que foi de 25,6\% para o mesmo período. Contraditoriamente, embora a pobreza tenha diminuído no estado, o Ceará apresentou um percentual de pessoas extremamente pobres na ordem de 18,4\%, proporção acima da média brasileira, que foi de 8,5\% (IBGE, 2010). Esse resultado classifica o Ceará como sendo o sétimo estado brasileiro com maior proporção de pessoas extremamente pobres para o ano de 2010.

No Brasil, há vários estudos que se propuseram a investigar os efeitos do crescimento econômico sobre a pobreza. São trabalhos que apresentam diferentes níveis de agregação e distintas metodologias, dentre os quais é oportuno citar os mais atuais: Taques e Rocha (2011), Pinto e Oliveira (2010), Salvato (2009), Manso et al. (2008), sendo algumas dessas pesquisas realizadas especificamente na Região Nordeste, como Gonçalves e Silveira Neto (2010) e Silveira Neto (2005).

Contudo, não há pesquisas de crescimento pró-pobre que contemplam como nível de análise estritamente o estado do Ceará. Considerando que o Ceará apresenta uma proporção de pessoas extremamente pobres acima da média brasileira, esta é uma importante motivação para a realização desse estudo.

Diante dessas assertivas e ao reconhecer a importância dos indicadores monetários como medida de pobreza, o objetivo deste artigo é verificar se o crescimento econômico do Ceará, tendo como nível de análise as áreas rurais e urbanas de suas microrregiões, tem sido pró-pobre, ou seja, se a renda dos pobres destas áreas tem apresentado uma elevação superior ao verificado pela renda dos não pobres, o que permite uma redução na desigualdade, conforme expõem Kakwani e Pernia (2000), e se tal crescimento tem sido empobrecedor, a saber, aquela modalidade de crescimento em que a renda dos mais ricos aumenta em uma proporção maior que a dos mais pobres.

Para atender a esse propósito, foram construídas as curvas de crescimento-pobreza para os anos de 2000 e 2010, proposta por Son (2004). Esta escolha se justifica no fato de este tipo de metodologia ponderar o crescimento econômico, acompanhado por uma redução na desigualdade de renda, uma vez que ela se baseia na curva de Lorenz. Esse atributo da metodologia de Son (2004) implica resultados mais conclusivos sobre a qualidade do crescimento econômico.

Dentre os resultados obtidos, constatou-se que apenas 14 das 33 microrregiões analisadas apresentam crescimento pró-pobre. Dentre essas microrregiões estão Forta- 
leza, Ibiapaba e Sobral. Ao separar as microrregiões por áreas urbana e rural, percebe-se que 23 do total apresentam crescimento em favor dos pobres em áreas urbanas (Baixo e Médio Jaguaribe, Fortaleza, Meruoca, Sobral etc.) e somente quatro experimentam essa modalidade de crescimento em áreas rurais (Brejo Santo, Caririaçu, Litoral de Aracati e Médio Curu). Esses resultados sugerem que o crescimento econômico é mais eficiente no combate à pobreza no meio urbano que no meio rural do estado.

Além das notas introdutórias, o presente artigo está distribuído em mais cinco outras seções. A segunda seção apresenta uma revisão bibliográfica acerca do crescimento pró-pobre. Na terceira seção é apresentada uma revisão da literatura e resultados empíricos do crescimento econômico, da pobreza e desigualdade de renda no estado do Ceará. A quarta seção expõe a base de dados e a forma de construção da curva de crescimento-pobreza. Por sua vez, a quinta seção mostra as curvas estimadas para as microrregiões cearenses e a discussão dos resultados, e a última seção é dedicada às principais conclusões do artigo.

\section{Crescimento pró-pobre: um breve relato}

Para o presente artigo, não é relevante fazer uma revisita extensa da literatura já existente sobre crescimento pró-pobre no mundo e no Brasil. Neste sentido, é imprescindível a apresentação de uma breve revisão de conceitos, metodologias e resultados. A discussão embrionária sobre crescimento pró-pobre teve início no "modelo de redistribuição com crescimento" de Chernery e Ahluwalia (1974), apud Kakwani, Khandker e Son (2004), que produziram nos últimos anos vastos estudos sobre o tema. Há várias abordagens que definem e mensuram o crescimento pró-pobre, usando vários critérios. Dentre estas definições podem-se citar basicamente a definição relativa de Kakwani e Pernia (2000) e a definição absoluta de Ravallion e Chen (2003).

Para Kakwani e Pernia (2000), o crescimento só será pró-pobre se a renda dos pobres apresentar elevação superior ao verificado pela renda dos não pobres, o que permite uma redução na desigualdade. Em outros termos, o crescimento pró-pobre ocorre quando se observa uma queda na pobreza maior que aquela que se teria se todas as rendas tivessem aumentado pela mesma taxa.

Na definição absoluta de Ravallion e Chen (2003), o crescimento pró-pobre ocorre quando a renda dos pobres aumenta à medida que há um crescimento da renda. Essa definição sugere que há esse tipo de crescimento se houver uma redução da pobreza, independentemente do que ocorrer na distribuição de renda. Portanto, mudanças na distribuição de renda não são consideradas.

Kakwani e Pernia (2000) utilizam como metodologia a decomposição proporcional. Neste caso, o índice de crescimento pró-pobre é dado pela razão da elasticidade renda-pobreza e da elasticidade crescimento-desigualdade. Deste modo, se o resultado obtido 
for maior que 1, então, teve-se um crescimento pró-pobre. Caso esteja situado entre 0 e 1, o crescimento não foi pró-pobre e, se for negativo, o crescimento foi empobrecedor. Vale ressaltar que Son (2004), partindo da definição de Kakwani e Pernia (2000), propôs a "curva de crescimento-pobreza", que tem como objetivo identificar se o crescimento econômico é ou não pró-pobre.

Em outra direção, Ravallion e Chen (2003) mensuraram o crescimento pró-pobre através da "curva de incidência do crescimento". Em síntese, o método parte do cálculo das taxas de crescimento das rendas de cada percentil da população em dois distintos instantes de tempo e detecta o crescimento pró-pobre no sentido absoluto (ou seja, a queda na pobreza é condição suficiente para que ocorra crescimento pró-pobre). Trabalhos como o de Kraay (2004) vão nessa direção. Nessa abordagem, os autores satisfazem o axioma da monotonicidade, porém não atendem ao axioma da transferência descrito em Sen (1976). Neste caso, percebem-se claramente distintas concepções e metodologias de crescimento pró-pobre. Contudo, em algumas pesquisas, o uso das diferentes metodologias, no Brasil, tem convergido para os mesmos resultados.

É o caso, por exemplo, de Salvato (2009) e Resende et al. (2007), que apesar de utilizarem metodologias distintas encontraram resultados semelhantes. Salvato (2009), ao estimar a "curva de incidência do crescimento" para as mesorregiões e microrregiões brasileiras nos anos de 1990, constatou que, de um total de 136 mesorregiões, apenas dez apresentavam crescimento pró-pobre. Ao utilizar a "curva de crescimento-pobreza", para o mesmo intervalo de tempo, Resende et al. (2007) também constataram para as capitais brasileiras preponderantemente resultados de crescimento com baixa ocorrência de crescimento pró-pobre.

Outro estudo também feito para a década de 1990 e que converge com resultados de Salvato (2009) e Resende et al. (2007) é o de Guidolin e Porto Júnior (2006). Das cem curvas de crescimento-pobreza que esses dois autores estimaram para os municípios da região Centro-Oeste, somente 14 desses municípios tiveram crescimento em favor dos pobres. Considerando o mesmo período de análise, vão nessa direção os trabalhos de Silveira Neto (2005) e Tejada et al. (2008) para regiões do Nordeste brasileiro.

\section{Crescimento econômico, pobreza e desigualdade de renda no estado do}

\section{Ceará entre 2000 e 2010}

Com o intuito de analisar se o crescimento econômico tem sido pró-pobre no estado do Ceará, atendendo, assim, o propósito desse artigo, torna-se pertinente um conhecimento prévio e sucinto acerca da evolução do crescimento econômico, da pobreza e da desigualdade de renda no último decênio no estado cearense. 


\subsection{Crescimento econômico}

O crescimento econômico é uma das variáveis que guarda estreita relação com a pobreza, pois, se ocorre crescimento, a tendência é que a pobreza diminua. Na maioria das vezes, costuma-se usar duas opções como forma de medir o crescimento econômico: o Produto Interno Bruto (PIB) ou a renda média.

Conforme já explicitado na seção anterior, além da metodologia da Curva de crescimento-pobreza de Son (2004), usada nesse artigo, a elasticidade-renda ou elasticidade-crescimento de Kakwani e Pernia (2000) se apresenta como uma das formas alternativas de medir a relação entre o crescimento econômico e a redução da pobreza. Se ocorrer elasticidade na relação mencionada, políticas públicas de combate à pobreza baseadas no crescimento econômico são mais eficientes. Caso contrário, sendo esta elasticidade inexpressiva, estratégias de redução da pobreza mais adequadas deveriam envolver uma combinação de crescimento econômico com algum tipo de redistribuição de renda (Marinho; Araújo, 2010).

Em outra direção, em um trabalho desenvolvido por Barro (1991) constata-se que os gastos com educação podem ser considerados produtivos, e por essa razão esses gastos deveriam ser compreendidos como investimento em capital humano. Conforme ressalta Santos (2008), em trabalho realizado com os municípios do estado do Ceará, os gastos públicos com capital humano representam maior retorno ao PIB per capita, sugerindo uma relação positiva entre maior investimento em educação e crescimento econômico na região.

Na mesma direção, Morais et al. (2012), ao investigarem a relação entre gastos públicos e crescimento econômico no Ceará, constataram que para cada aumento de $1 \%$ em capital humano o produto eleva-se em aproximadamente $0,14 \%$, enquanto para cada aumento de $1 \%$ do capital físico per capita o crescimento do produto é somente de 0,05\%. Evidência que reforça a assertiva de que políticas públicas direcionadas à educação se configuram em um elemento-chave para o aumento em produtividade e aumentos no crescimento econômico de longo prazo.

De forma a captar as assertivas expostas acima para a realidade do Ceará, é apresentada na Figura 1 a taxa de crescimento do PIB a preço constante do Ceará na última década. Espera-se que, à medida que o PIB evolua, o crescimento econômico também aconteça. De fato, é possivel perceber, da análise da referida figura, que, no último ano, teve-se um crescimento do PIB de aproximadamente $8 \%$, representando um crescimento de mais de $5 \%$ em relação ao ano anterior. É de fácil percepção, também, que o Ceará obteve um crescimento linear do seu PIB. Conclui-se que o crescimento econômico vem acontecendo no decorrer dos últimos anos e que esse crescimento tem sido linear. 


\section{Figura 1 - Taxa de crescimento do PIB a preço constante entre 2000 e 2010 (em \%).}

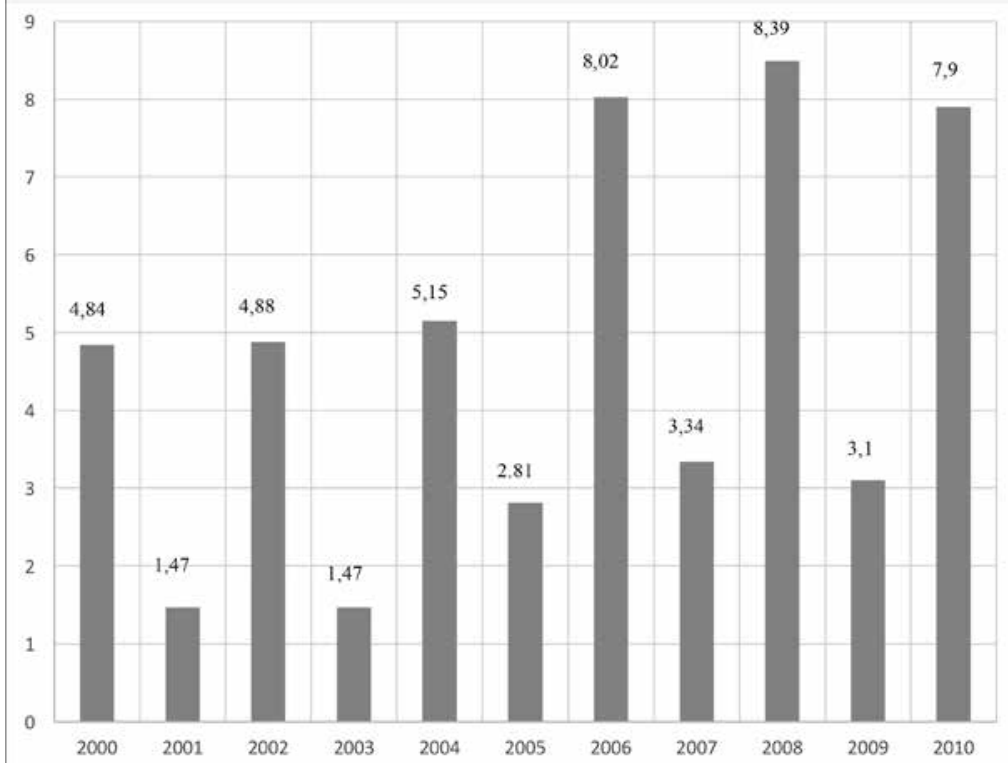

Fonte: Construída pelos autores com base nos dados do IPECE (2012).

Ainda na mesma perspectiva, dados do IBGE (2010) revelam que, se forem comparados o desempenho da economia cearense e da brasileira em toda a década, percebe-se que, de um modo geral, ambas seguem a mesma trajetória, exceto no ano de 2007, no qual o Ceará apresentou um declínio de crescimento, enquanto o país permaneceu em processo de expansão. Tal fato mostra que o estado do Ceará tem se comportado aos longos dos anos em quase que perfeita sintonia com o crescimento do país, ao menos em termos de PIB.

\subsection{Pobreza}

A pobreza é um fenômeno multidimensional, e, sendo assim, existem múltiplas definições e formas de avaliá-la. Entretanto, tradicionalmente, a pobreza é definida como privação material, medida pela renda ou consumo do indivíduo ou da família. Neste caso, fala-se de pobreza extrema ou absoluta diante da insuficiência de rendimentos para satisfazer as necessidades alimentares básicas de uma pessoa, sendo, muitas vezes, expressas em termos de requisitos calóricos mínimos. Além disso, há a definição de pobreza relativa, que é a insuficiência de renda para satisfazer necessidades alimentares básicas e necessidades não básicas, ou seja, vestuário, habitação e energia (UNDP, 2000). Na literatura brasileira, existem vários trabalhos com essa abordagem, como, por exemplo, Rocha (2000), Hoffman (1998), Barros, Carvalho e Franco (2003) e Barreto (2005), entre outros. 
Em 2011, o Ministério do Desenvolvimento Social e Combate à Fome (MDS) estabeleceu o valor de renda familiar mensal de $\mathrm{R} \$ 70,00$ por pessoa como linha de miséria, quando do lançamento do Programa de Erradicação da Extrema Pobreza do Governo Federal. Diante dessa adotada linha de extrema pobreza, o Instituto Brasileiro de Geografia e Estatística (IBGE) disponibilizou um conjunto de dados relativos à população e aos domicílios particulares permanentes sem rendimento e com rendimento nominal mensal domiciliar per capita inferior a setenta reais (Taques; Rocha, 2011).

De acordo com esses dados, o estado do Ceará possuía, em 2010, cerca de 1.502.924 moradores residentes em domicílios com rendimentos mensais por pessoa que não ultrapassavam o valor de $\mathrm{R} \$ 70,00$ (IBGE, 2010). Isso significa que 17,8\% da população cearense foram classificados como miseráveis, com base no parâmetro estabelecido pelo MDS. Em termos proporcionais, o Ceará é o sétimo estado da Federação com maior percentual de pessoas nessa condição. Já em termos de participação relativa, dos 16,3 milhões de brasileiros nesta faixa de renda domiciliar per capita, 9,24\% estão localizados no Ceará. Sendo assim, o estado é o terceiro do Brasil com maior contingente de pessoas extremamente pobres ou miseráveis, atrás da Bahia (14,80\%) e do Maranhão (10,40\%).

Dados do IBGE (2012) comprovam que a incidência de pobreza é mais elevada na Região Nordeste que nas demais regiões, sendo que o estado do Ceará, por exemplo, apresenta taxas de pobreza em um nível muito acima da média brasileira. Contudo, com base nos dados da Pesquisa Nacional por Amostras em Domicílio (PNAD) do IBGE, percebe-se que, enquanto o Brasil como um todo apresentou entre os anos de 2001 e 2011, uma redução de 38,9\% nos níveis de pobreza, o Ceará reduziu sua proporção de pobres em 31,3\%, um pouco acima da Região Nordeste, que apresentou uma redução de 30,3\%.

Analisando a pobreza sob o aspecto rural e urbano, o que se nota é que a zona rural do Ceará apresenta o maior percentual de pessoas pobres, enquanto a região metropolitana de Fortaleza (RMF) apresenta um percentual inferior à média nacional. Ainda é possível verificar que esse abismo social tem aumentado ao longo do tempo, devido à redução mais acentuada da pobreza na $\operatorname{RMF}(38,5 \%)$ e na zona urbana (33,4\%), enquanto a zona rural apresenta a menor redução (20,2\%) IBGE (2012).

Após fixar a linha de extrema pobreza - linha de miséria -, o Governo Federal comprometeu-se a erradicá-la até 2014. Portanto, é de suma importância acompanhar a evolução deste indicador para verificar se a meta será atingida. A evolução da proporção de pessoas extremamente pobres, entre o período de 2001 e 2011, pode ser visualizada pela Tabela 1. 
140 - Os efeitos do crescimento econômico na pobreza do Ceará: uma análise microrregional

Tabela 1 - Proporção de pessoas em extrema pobreza no Brasil, no Nordeste e no Ceará entre 2001 e 2011 (em \%)

\begin{tabular}{cccc}
\hline Período & Brasil & Nordeste & Ceará \\
2001 & 11,2 & 22,2 & 22,4 \\
2002 & 10,0 & 20,7 & 20,0 \\
2003 & 11,4 & 22,9 & 21,6 \\
2004 & 9,1 & 19,3 & 18,8 \\
2005 & 7,5 & 16,4 & 17,5 \\
2006 & 6,4 & 14,2 & 15,0 \\
2007 & 6,2 & 13,5 & 14,3 \\
2008 & 5,1 & 11,1 & 13,0 \\
2009 & 5,2 & 11,0 & 10,9 \\
2011 & 4,8 & 10,2 & 10,1 \\
\hline
\end{tabular}

Fonte: IBGE/PNAD (2012).

Os dados evidenciam que o percentual de pessoas em extrema pobreza tem se reduzido ao longo do tempo, mas a diferença entre as taxas de extrema pobreza do Nordeste e do Ceará em relação ao Brasil se mantém elevada. O Brasil reduziu em 57,6\% o percentual de pessoas em extrema pobreza, enquanto o Nordeste brasileiro e o estado do Ceará reduziram em $54,2 \%$ e $54,6 \%$, respectivamente.

\subsection{Desigualdade de renda}

A desigualdade de renda é um dos pilares do entendimento do que se pode fazer para melhorar qualidade de vida de qualquer país. Se forem analisados os diversos trabalhos que abordam o assunto, ver-se-á que tornar a distribuição de renda mais justa traz benefícios e ganhos, não apenas para os menos favorecidos, mas também para todos de maneira geral. Ainda há de se considerar o fato de que, conforme expõem Bourguignon (2002) e Ravallion (1997), a redução da desigualdade de renda é um instrumento importante na redução da pobreza. Em contrapartida, a redução da pobreza pode ser alcançada com mais rapidez quando se tem uma distribuição de renda mais justa (Barreto, 2005).

Percebe-se que a busca por soluções que venham a sanar a desigualdade, o que geralmente se faz através de políticas públicas, além de resolver o problema específico, ainda pode atingir outras metas de política econômica, como o aumento do crescimento e da diminuição da pobreza. Marinho e Soares (2003), após realizarem uma estimação das elasticidades renda-pobreza para os estados brasileiros, constataram que a pobreza apresenta maior sensibilidade em relação à desigualdade do que ao crescimento econômico. 
Segundo esses autores, se o custo de reduzir 1\% da concentração de renda for igual ao custo de aumentar a renda em 1\%, a redução da concentração de renda seria o mecanismo mais eficaz para reduzir a pobreza.

Contudo, Marinho e Soares (2003) ressaltam que os dois processos, desconcentração de renda e crescimento econômico, não são excludentes e que o crescimento pode vir acompanhado de uma redução na desigualdade ${ }^{1}$.

Segundo Stewart (2000) e Fosu (2010), uma elevada desigualdade de renda proporciona instabilidade política, incerteza, menores investimentos e baixos níveis de crescimento. Embora essa preocupação com a desigualdade só tenha vindo a ser uma pauta importante na política do governo na última década, após os grandes problemas enfrentados com a inflação inercial existente no Brasil, se o País almeja um crescimento de fato, terá que estar preparado para vencer os problemas citados anteriormente.

Através da Figura 2, é possível observar que a década de 2000 trouxe saldos realmente positivos para a desigualdade no Brasil. A análise do índice de Gini, que mede a desigualdade na distribuição de renda domiciliar per capita, permite mostrar que houve uma redução da concentração de renda durante os últimos anos. Fazendo um estudo comparativo em relação aos resultados alcançados no Ceará com os do Nordeste e Brasil, pode-se notar não só as melhoras alcançadas pelo Ceará, como o seu desempenho diante dos demais componentes da Federação. Assim sendo, percebe-se que o Ceará apresentou a maior redução média na desigualdade, que foi da ordem de 12,08\%, contra 11,31\%, e 9,58\%, do Brasil e do Nordeste, respectivamente.

\section{Figura 2 - Índice de Gini no Brasil, Nordeste e Ceará entre 2001 e 2011.}

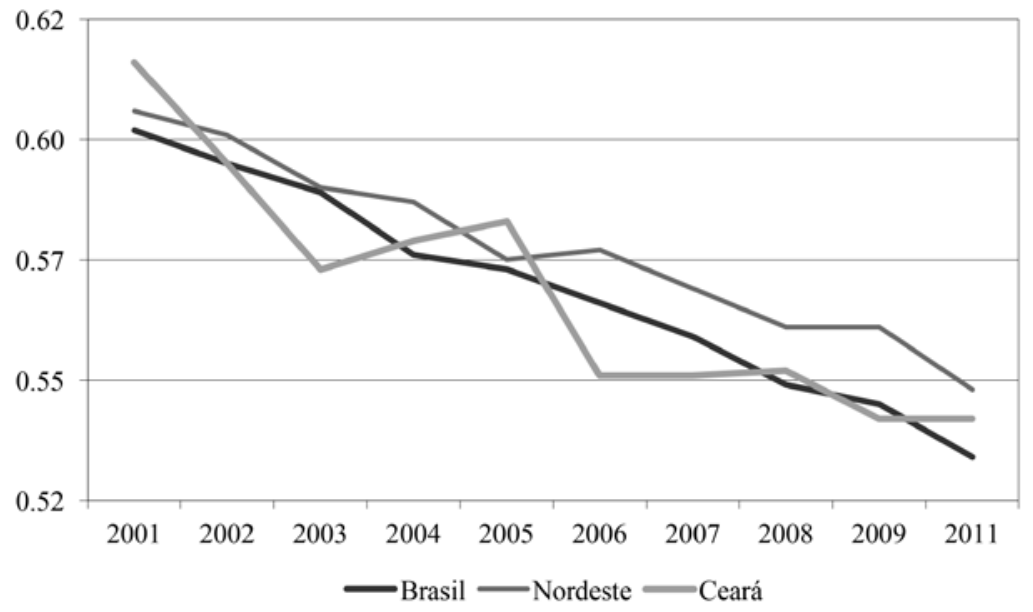

Fonte: Construída pelos autores com base nos dados das Pnads 2001 e 2011.

1 A Seção 2 mostrou evidências empíricas comprovando essa assertiva. 
Fica evidente, de acordo com os dados da Figura 2, que a desigualdade de renda no Ceará vem oscilando nos últimos tempos. Essas oscilações na trajetória do índice de Gini, em parte, podem ser explicadas pelo comportamento da desigualdade nas diferentes áreas geográficas do estado. Não obstante, observe que se tem maiores índices de redução entre 2001 e 2003 e entre 2005 e 2006.

Outra análise acerca da desigualdade, agora sob o prisma das regiões geográficas do Ceará, mostra que ela tem se mostrado positiva para a RMF e negativa para a zona rural e urbana nos últimos anos. Para se ter uma ideia, ao longo do período 2000-2011, a desigualdade caiu 17,48\% na RMF, 9,34\% na zona rural e aumentou 4,83\% na zona urbana, de acordo com dados do IBGE (2012).

Outra forma de se analisar o comportamento da desigualdade é através da observação da proporção da renda apropriada pelos percentis da população. No Ceará, essa proporção caiu para as camadas mais ricas em $8 \%$. Em contrapartida, a parcela apropriada pelos mais pobres cresceu em 3\%. Em 2001, os 10\% mais ricos se apoderavam de mais de $51 \%$ de toda a renda, enquanto a parcela destinada aos 50\% mais pobres era de quase $13 \%$. Em 2011, a participação dos 10\% mais ricos passou a ser de menos de 43\%, enquanto a parcela dos 50\% mais pobres aumentou para 16\% (IBGE, 2012).

Diante do exposto, ficam claras as melhorias alcançadas pelo estado do Ceará tanto em crescimento quanto em redução da pobreza e da desigualdade de renda. Pode-se ainda concluir que esse avanço é comparativamente melhor daquele apresentado pela Região Nordeste nos últimos anos, ficando o estado cearense cada vez mais próximo de alcançar a média nacional para todas as variáveis aqui analisadas e discutidas.

\section{Base de dados e metodologia da curva de crescimento-pobreza}

As variáveis utilizadas neste artigo para construir as curvas de crescimento-pobreza foram retiradas dos microdados dos Censos dos anos de 2000 e 2010, disponibilizados pelo Instituto Brasileiro de Geografia e Estatística (IBGE). Esta base de dados foi escolhida por representar a totalidade da população brasileira e trazer informações detalhadas sobre rendimentos.

As curvas crescimento-pobreza foram estimadas através dos dados da renda domiciliar per capita para as 33 microrregiões cearenses distribuídas nas sete mesorregiões do estado. As microrregiões estão descritas na Tabela 2. 
Tabela 2 - Relação das microrregiões cearenses por mesorregião.

\begin{tabular}{llll}
\hline Sul & Sertões Cearenses & Jaguaribe & Fortaleza \\
Barro & Sertão de Crateús & Baixo Jaguaribe & Fortaleza \\
Brejo Santo & Sertão de Inhamuns & Litoral de Aracati & Pacajus \\
Cariri & Sertão de Quixeramobim & Médio Jaguaribe & \\
Caririaçu & Sertão de Senador Pompeu & Serra do Pereiro & \\
Chapada do Araripe & & & \\
\hline Norte & Noroeste Cearense & Centro Sul & \\
\hline Baixo Curu & Coreaú & Iguatu & \\
Baturité & Ibiapaba & Lavras da Mangabeira & \\
Canindé & Ipu & Várzea Alegre & \\
Chorozinho & Santa Quitéria & & \\
Itapipoca & Meruoca & & \\
Médio Curu & Litoral de Camocim/Acaraú & & \\
Cascavel & Sobral & & \\
Uruburetama & & & \\
\hline
\end{tabular}

Fonte: Elaboração dos autores com base no IBGE/2010.

\subsection{Curva de Crescimento-Pobreza}

A curva de crescimento-pobreza (poverty growth curve - PGC) de Son (2004) utiliza o conceito relativo de crescimento "pró-pobre" de Kakwani \& Pernia (2000) e tem origem no teorema de Atkinson $(1987)^{2}$, que associa mudanças na curva de Lorenz generalizada à variação de um índice de pobreza. Se a curva de Lorenz for representada por uma reta positivamente inclinada, a região em análise apresenta perfeita igualdade de renda, $L(p)=\mathrm{p}$. Se a curva se desloca para a esquerda (direita), tem-se redução (aumento) da pobreza e o crescimento é pró-pobre (não pró-pobre).

A descrição da metodologia de Son (2004, p. 308-309) é dada a partir da seguinte equação:

$$
L(p)=\frac{1}{\mu} \int_{0}^{x} y f(y) d y
$$

Em que:

$$
p=\int_{0}^{x} f(y) d y
$$

Assim, $L(p)$ representa a curva de Lorenz que descreve a participação na renda da população situada entre os $p \%$, assumindo que a população está ordenada de forma cres-

2 Veja Atkinson, A. B. (1987), "On the Measurement of Poverty", Econometrica, 55(4), p. 49-64. 
cente segundo sua renda. A média da renda da população é dada por $\mu$ e a renda pessoal assume o valor $y$ com probabilidade expressa pela função densidade representada por $f(y)$. Deste modo, $\mu L(p)$ representa a curva de Lorenz generalizada.

Mudanças na curva de Lorenz indicam que a desigualdade modifica-se com o crescimento econômico. Logo, se a curva de Lorenz generalizada se aproxima da curva de perfeita igualdade, ou seja, se esta curva se desloca para a esquerda (cima), o crescimento é pró-pobre $\Delta L(p) \geq 0$ para todo $p$. Isso ocorre quando a nova distribuição é dominante sobre a distribuição anterior, tendo assim a dominância de segunda ordem ou a chamada curva de segunda ordem dominante.

A equação (3) é extraída da definição da curva de Lorenz:

$$
L(p)=\frac{\mu_{p} p}{\mu}
$$

Mostra a participação na renda dos p\% mais pobres, quando é apresentada a fórmula da curva de Lorenz, em que, $\mu_{p}$ é a renda média dos primeiros $p$ percentis da população. Calculando o logaritmo de ambos os lados de (3) obtém-se:

$$
\operatorname{Ln}\left(\mu_{p}\right)=\operatorname{Ln}(\mu L(p))-\operatorname{Ln}(p)
$$

Ao aplicar a primeira diferença na equação acima, ter-se-á:

$$
\begin{aligned}
g(p) & =\Delta L n(\mu L(p)) \\
\text { e } \quad g(p) & =\Delta \operatorname{Ln}\left(\mu_{p}\right)
\end{aligned}
$$

A equação (5) pode ser reescrita da seguinte forma:

$$
g(p)=\Delta L n(L(p)), \text { sendo } g=\Delta L n(\mu)
$$

em que $g$ representa a taxa de crescimento da renda média da sociedade e $g(p)$ por sua vez mede a taxa de crescimento da renda média até o decil $p$. A expressão (7) é, portanto, a curva de crescimento-pobreza.

A partir dessa metodologia, o crescimento econômico poderá resultar em quatro possíveis cenários para a pobreza:

i. Pró-pobre $g(p)>g$ para todo $p<100$ : cenário em que há uma redução da pobreza entre os períodos, pois a curva de Lorenz, como um todo, se desloca para esquerda ( $L$ (p) > 0 para todo $\mathrm{p}$ );

ii. Não pró-pobre (ou pró-rico) $0<g(p)<g$ para todo $p<100$ : o crescimento eco- 
nômico induziu a uma queda na pobreza, porém, com um aumento da concentração de renda $(L(p)<0$ para todo $\mathrm{p})$. Esse é o caso do crescimento trickle-down, que, apesar de contribuir para reduzir a pobreza, a renda dos ricos cresce em uma proporção maior que a renda dos pobres;

iii. Empobrecedor: Se $g(p)<g$ para todo $p<100$ e se $g>0$, (ou $g(p)<0$ para todo $p$ $<100$ e $g>0$ ), então há um crescimento empobrecedor, pois o crescimento econômico aumenta a pobreza devido à queda na renda do p mais pobres $(g(p)<0)$, apesar do crescimento da renda média $(g>0)$.

iv. Inconclusivo: casos omissos.

\section{Evidências produzidas}

As evidências apresentadas e discutidas neste tópico resultam de um total de 800.612 e 817.916 observações extraídas dos Censos de 2000 e 2010, respectivamente. Foram estimadas 99 Curvas de Crescimento-pobreza para as 33 microrregiões cearenses, divididas entre as áreas urbanas, rurais e para a área geral, como um todo, de cada microrregião.

As quatro primeiras colunas das Tabelas 3, 4 e 5 mostram a taxa de crescimento da renda média da população até o percentil $p$, denominado como $g(p)$. A primeira coluna das referidas tabelas apresenta os valores estimados da taxa de crescimento da renda média dos $20 \%$ mais pobres da população. A segunda coluna apresenta a taxa de crescimento da renda média desses 20\% mais pobres, acrescidos dos $20 \%$ seguintes (ou seja, dos $40 \%$ mais pobres). Sendo que a última coluna equivale à taxa de crescimento da renda média da totalidade da população, neste caso, $g(p)=g$.

Conforme relata Son (2004) em sua metodologia, se a taxa de crescimento da renda média para todos os percentis da população for maior que a taxa de crescimento da renda média da totalidade da população, ter-se-á crescimento pró-pobre, pois a curva de Lorenz, com um todo, se aproximou da reta de perfeita igualdade, tendo, portanto, um crescimento econômico combinado a uma redução da desigualdade.

Nesse sentido, ao analisar as microrregiões como um todo, a Tabela 3 evidencia que, de 2000 a 2010, houve crescimento econômico acompanhado de redução da desigualdade de renda, crescimento pró-pobre, em apenas 14 microrregiões. Em termos percentuais, isso corresponde a $42 \%$ das microrregiões. Este é o caso de Fortaleza, Ibiapaba, Sobral, dentre outras. Em dezoito microrregiões nada se pode concluir sobre a qualidade do crescimento, pois, embora se obtivesse valores de $g(p)$ superiores ao de $g$ para alguns percentis, para outros isso não ocorre. Dentre essas microrregiões que apresentam resultados inconclusivos estão Baturité, Iguatu, Itapipoca etc. 
146 - Os efeitos do crescimento econômico na pobreza do Ceará: uma análise microrregional

Tabela 3 - Estimativa da Curva de Crescimento-Pobreza para as Microrregiões Cearenses (2000-2010).

\begin{tabular}{|c|c|c|c|c|c|}
\hline Microrregiões & $20 \%$ & $40 \%$ & $60 \%$ & $80 \%$ & $100 \%$ \\
\hline Baixo Curu & 1.2917 & 1.2166 & 1.2206 & 1.2073 & 1.1594 \\
\hline Baixo Jaguaribe & 1.0297 & 1.1390 & 1.1614 & 1.1543 & 1.0102 \\
\hline Barro & 0.9304 & 1.0523 & 1.1272 & 1.1463 & 1.0144 \\
\hline Baturité & 1.0012 & 1.1039 & 1.1376 & 1.1356 & 1.0447 \\
\hline Brejo Santo & 1.2284 & 1.2322 & 1.2058 & 1.1506 & 0.9634 \\
\hline Canindé & 0.8124 & 0.9662 & 1.0607 & 1.0855 & 1.0172 \\
\hline Cariri & 1.1852 & 1.1991 & 1.1697 & 1.1351 & 0.9785 \\
\hline Caririaçu & 1.2987 & 1.3081 & 1.3041 & 1.2465 & 1.1293 \\
\hline Cascavel & 1.0597 & 1.1747 & 1.1947 & 1.1925 & 0.9239 \\
\hline Chapada do Araripe & 0.8673 & 1.0547 & 1.1807 & 1.2496 & 1.0207 \\
\hline Chorozinho & 0.9433 & 1.1460 & 1.1809 & 1.1978 & 1.1383 \\
\hline Coreaú & 1.0069 & 1.1056 & 1.1592 & 1.1850 & 1.1006 \\
\hline Fortaleza & 1.0527 & 1.0470 & 1.0043 & 0.9282 & 0.8150 \\
\hline Ibiapaba & 2.4323 & 1.1827 & 1.1999 & 1.1836 & 1.0987 \\
\hline Iguatu & 0.9205 & 1.0816 & 1.1182 & 1.1036 & 1.0253 \\
\hline Ipu & 1.0371 & 1.1118 & 1.1515 & 1.1528 & 1.0897 \\
\hline Itapipoca & 0.7511 & 0.9464 & 1.0354 & 1.0499 & 0.9571 \\
\hline Lavras da Mangabeira & 1.0756 & 1.1849 & 1.2293 & 1.2304 & 1.2404 \\
\hline Litoral de Aracati & 0.9945 & 1.1063 & 1.1046 & 1.0863 & 0.9742 \\
\hline Litoral de Camocim/Acaraú & 0.9937 & 1.0970 & 1.1415 & 1.1607 & 1.0852 \\
\hline Médio Curu & 1.1008 & 1.0804 & 1.1881 & 1.1319 & 0.9772 \\
\hline Médio Jaguaribe & 0.8256 & 0.9930 & 1.0444 & 1.0645 & 0.9090 \\
\hline Meruoca & 1.3315 & 1.3875 & 1.3090 & 1.2139 & 1.0534 \\
\hline Pacajus & 1.1786 & 1.2013 & 1.1918 & 1.1749 & 0.9269 \\
\hline Santa Quitéria & 1.6403 & 1.9403 & 2.0320 & 1.6816 & 1.3398 \\
\hline Serra do Pereiro & 0.8647 & 1.0145 & 1.0784 & 1.0647 & 0.9054 \\
\hline Sertão de Crateús & -0.7757 & -0.9258 & -0.9536 & -0.6168 & -0.4344 \\
\hline Sertão de Inhamuns & 1.0478 & 1.1996 & 1.2421 & 1.2212 & 1.0930 \\
\hline Sertão de Quixeramobim & 0.7526 & 0.9499 & 1.0518 & 1.0766 & 1.0324 \\
\hline Sertão de Senador Pompeu & 0.8182 & 0.9846 & 1.0640 & 1.0886 & 0.9250 \\
\hline Sobral & 1.0418 & 1.1377 & 1.1645 & 1.1564 & 1.0161 \\
\hline Uruburetama & 0.6909 & 0.8908 & 1.0010 & 1.0321 & 0.9723 \\
\hline Várzea Alegre & 0.8382 & 1.0185 & 1.0903 & 1.1293 & 1.0597 \\
\hline
\end{tabular}

Fonte: Construída pelos autores a partir de dados dos Censos de 2000 e 2010. 
Conforme se observa, Lavras da Mangabeira, Uruburetama e Várzea Alegre estão entre aquelas microrregiões em que o crescimento econômico não foi eficaz para beneficiar sobretudo os mais pobres. Marinho e Araújo (2012) ressaltam que regiões com alta desigualdade inicial apresentam condições menos favoráveis à redução da pobreza via crescimento da renda. Essa evidência parece justificar o baixo desempenho do crescimento em reduzir a pobreza nessas três microrregiões, uma vez que Mayorga et al. (2007), tendo como referência o Índice Regional de Desigualdade de Theil construído para as microrregiões cearenses, apontaram que as microrregiões supracitadas estão entre aquelas que apresentaram um aumento da desigualdade no período de 1997 a 2002.

Silveira Neto (2005) obteve resultados semelhantes aos da Tabela 3 ao estimar as curvas de crescimento-pobreza para 188 microrregiões do Nordeste brasileiro, no período de 1991 a 2000. O autor constatou que apenas 11 dessas microrregiões apresentavam crescimento pró-pobre. Na mesma direção, Gonçalves e Silveira Neto (2010), ao utilizarem o período de análise de Silveira Neto (2005), observaram, ao estimar as curvas de crescimento-pobreza para os municípios cearenses, que apenas 21 de um total de 1.031 municípios apresentaram crescimento em favor dos pobres.

Quando se compara os expressivos valores do PIB a preço constante apresentados na Figura 1 com os resultados da Tabela 3, constata-se que as altas taxas de crescimento do PIB não resultam necessariamente em crescimento pró-pobre para o período analisado. Essa relevante constatação reforça a assertiva de que, talvez, mais importante que crescer é saber como crescer, ou seja, qual modelo de crescimento econômico explorar.

Ao separar as microrregiões entre áreas urbana e rural, percebe-se claramente que as baixas ocorrências de crescimento pró-pobre para as microrregiões do Ceará, como um todo, são devidas ao baixo desempenho do crescimento econômico em reduzir a pobreza, com queda na desigualdade nas áreas rurais. A Tabela 4 mostra que, quando se analisa estritamente a área urbana, o crescimento é para os pobres em 23 das 33 microrregiões (Baixo e Médio Jaguaribe, Fortaleza, Meruoca, Sobral etc.), algo que representa $70 \%$ das microrregiões. Não há incidência de crescimento trickle-down, ou seja, aquele crescimento que promove redução de pobreza, porém, com aumento da desigualdade. Para outras dez microrregiões os resultados gerados são inconclusivos. 
148 - Os efeitos do crescimento econômico na pobreza do Ceará: uma análise microrregional

Tabela 4 - Estimativa da Curva de Crescimento-Pobreza para a Área Urbana das Microrregiões Cearenses (2000-2010).

\begin{tabular}{|c|c|c|c|c|c|}
\hline Microrregiões & $20 \%$ & $40 \%$ & $60 \%$ & $80 \%$ & $100 \%$ \\
\hline Baixo Curu & 1.1190 & 1.1801 & 1.1689 & 1.1556 & 1.0841 \\
\hline Baixo Jaguaribe & 1.0878 & 1.1206 & 1.1248 & 1.0999 & 0.9227 \\
\hline Barro & 1.0431 & 1.0880 & 1.1005 & 1.0668 & 0.8436 \\
\hline Baturité & 1.0167 & 1.0594 & 1.0691 & 1.0397 & 0.9511 \\
\hline Brejo Santo & 0.8971 & 0.9504 & 0.9422 & 0.8907 & 0.6930 \\
\hline Canindé & 0.7363 & 0.9193 & 0.9605 & 0.9884 & 0.9135 \\
\hline Cariri & 1.1947 & 1.1585 & 1.1170 & 1.0928 & 0.9372 \\
\hline Caririaçu & 1.0771 & 1.1028 & 1.1143 & 1.0602 & 0.9756 \\
\hline Cascavel & 1.0826 & 1.1660 & 1.1790 & 1.1718 & 0.8639 \\
\hline Chapada do Araripe & 0.9593 & 1.0587 & 1.0901 & 1.1231 & 0.9135 \\
\hline Chorozinho & 1.0281 & 1.1465 & 1.1644 & 1.1805 & 1.0809 \\
\hline Coreaú & 0.9619 & 1.0967 & 1.1610 & 1.1823 & 1.0466 \\
\hline Fortaleza & 1.0528 & 1.0455 & 1.0034 & 0.9276 & 0.8204 \\
\hline Ibiapaba & 1.0623 & 2.3924 & 2.3381 & 1.1050 & 1.0420 \\
\hline Iguatu & 1.0592 & 1.0954 & 1.0934 & 1.0679 & 0.9925 \\
\hline Ipu & 0.9854 & 1.0460 & 1.0586 & 1.0602 & 1.0123 \\
\hline Itapipoca & 0.9809 & 1.0587 & 1.0699 & 1.0398 & 0.9317 \\
\hline Lavras da Mangabeira & 0.9404 & 1.0460 & 1.0721 & 1.1030 & 1.0879 \\
\hline Litoral de Aracati & 0.9772 & 1.0693 & 1.0747 & 1.0523 & 0.9806 \\
\hline Litoral de Camocim/Acaraú & 1.0900 & 1.1158 & 1.1087 & 1.1169 & 1.0057 \\
\hline Médio Curu & 1.0558 & 1.1047 & 1.1348 & 1.1326 & 1.0060 \\
\hline Médio Jaguaribe & 0.9849 & 1.0148 & 1.0066 & 0.9869 & 0.8142 \\
\hline Meruoca & 1.4675 & 1.4360 & 1.2694 & 1.1425 & 0.9641 \\
\hline Pacajus & 1.2107 & 1.1901 & 1.1761 & 1.1580 & 0.8774 \\
\hline Santa Quitéria & 0.8805 & 0.9963 & 1.0215 & 1.0388 & 0.8962 \\
\hline Serra do Pereiro & 0.8964 & 0.9597 & 0.9354 & 0.8946 & 0.7490 \\
\hline Sertão de Crateús & 0.8975 & 1.0028 & 1.0549 & 1.0390 & 0.9613 \\
\hline Sertão de Inhamuns & 1.1105 & 1.1286 & 1.1261 & 1.0908 & 0.9388 \\
\hline Sertão de Quixeramobim & 0.8881 & 1.0235 & 1.0468 & 1.0301 & 0.9671 \\
\hline Sertão de Senador Pompeu & 0.9029 & 0.9939 & 1.0255 & 1.0108 & 0.8009 \\
\hline Sobral & 1.0475 & 1.1077 & 1.1186 & 1.0983 & 0.9507 \\
\hline Uruburetama & 0.7979 & 1.0076 & 1.0452 & 1.0367 & 0.9601 \\
\hline Várzea Alegre & 0.9793 & 1.0515 & 1.0724 & 1.0636 & 0.9658 \\
\hline
\end{tabular}

Fonte: Construída pelos autores a partir de dados dos Censos de 2000 e 2010. 
Por outro lado, ao examinar a Tabela 5, representada exclusivamente pela área rural, verifica-se crescimento pró-pobre em apenas quatro microrregiões, Brejo Santo, Caririaçu, Litoral de Aracati e Médio Curu, correspondendo a 12\% das microrregiões. Observe que dez do total de microrregiões apresentam um crescimento de natureza trickle-down, já que a renda média dos mais ricos cresce em uma proporção maior que a renda dos mais pobres. Dentre essas microrregiões estão Pacajus e Canindé. Veja, por exemplo, o caso de Baixo Curu, em que a taxa de crescimento da renda média dos 20\%, 40\%, 60\% e $80 \%$ mais pobres é de respectivamente 1,01\%,1,22\%,1,13\% e 1,26\%, inferior à taxa de crescimento da renda média da população total, que é de 1,30\%.

\section{Tabela 5 - Estimativa da Curva de Crescimento-Pobreza para a Área Rural das Microrregiões Cearenses (2000-2010).}

\begin{tabular}{l|ccccc}
\hline Microrregiões & $20 \%$ & $40 \%$ & $60 \%$ & $80 \%$ & $100 \%$ \\
\hline Baixo Curu & 1.0182 & 1.2201 & 1.1335 & 1.2660 & 1.3011 \\
Baixo Jaguaribe & 0.8525 & 1.0459 & 2.3320 & 2.3173 & 1.0680 \\
Barro & 0.8914 & 0.8610 & 0.9836 & 1.0571 & 1.0905 \\
Baturité & 0.9519 & 1.0934 & 1.1562 & 1.1862 & 1.1694 \\
Brejo Santo & 1.2171 & 1.2726 & 1.2563 & 1.2215 & 1.0520 \\
Canindé & 0.9641 & 0.8628 & 1.0449 & 1.1349 & 1.1488 \\
Cariri & 0.9618 & 1.0998 & 1.1625 & 1.1743 & 1.0797 \\
Caririaçu & 1.3414 & 1.2721 & 1.2962 & 1.2975 & 1.2038 \\
Cascavel & 0.9735 & 1.1287 & 1.1858 & 1.1933 & 1.0626 \\
Chapada do Araripe & 0.7770 & 0.7378 & 0.9398 & 1.0456 & 0.9952 \\
Chorozinho & 0.8571 & 1.0631 & 1.1256 & 1.1618 & 1.1275 \\
Coreaú & 1.1606 & 1.0497 & 1.1138 & 1.1306 & 1.1534 \\
Fortaleza & 1.1574 & 1.2566 & 1.2689 & 1.2446 & 1.1650 \\
Ibiapaba & 1.0938 & 1.1559 & 1.2003 & 1.2076 & 1.1396 \\
Iguatu & 0.7904 & 0.8940 & 1.0206 & 1.0649 & 0.9838 \\
Ipu & 1.1048 & 1.0622 & 1.1384 & 1.1870 & 1.1489 \\
Itapipoca & 0.7841 & 0.7376 & 0.9087 & 0.9822 & 0.9267 \\
Lavras da Mangabeira & 1.1128 & 1.1865 & 1.2857 & 1.3083 & 1.4110 \\
Litoral de Aracati & 1.0543 & 1.1759 & 1.1858 & 1.1739 & 1.0245 \\
Litoral de Camocim/Acaraú & 1.0175 & 0.9818 & 1.0987 & 1.1678 & 1.2054 \\
Médio Curu & 1.1977 & 1.0572 & 1.0730 & 1.1058 & 0.9031 \\
Médio Jaguaribe & 0.6219 & 0.7258 & 0.8851 & 0.9216 & 0.8908 \\
Meruoca & 1.1734 & 1.3054 & 1.2891 & 1.2271 & 1.1734 \\
Pacajus & 0.7051 & 1.0363 & 1.1139 & 1.1162 & 1.1190 \\
& & & & & \\
\hline
\end{tabular}


(continuação)

\begin{tabular}{l|ccccc}
\hline Microrregiões & $20 \%$ & $40 \%$ & $60 \%$ & $80 \%$ & $100 \%$ \\
\hline Santa Quitéria & 1.0873 & 0.9807 & 1.0405 & 1.0730 & 1.1001 \\
Serra do Pereiro & 0.8731 & 0.9402 & 1.0581 & 1.1572 & 1.0995 \\
Sertão de Crateús & 0.9345 & 0.8053 & 0.9510 & 1.0494 & 1.0128 \\
Sertão de Inhamuns & 1.0153 & 1.0510 & 1.1838 & 1.2166 & 1.1824 \\
Sertão de Quixeramobim & 0.8082 & 0.7092 & 0.8792 & 0.9784 & 0.9869 \\
Sertão de Senador Pompeu & 0.8574 & 0.8133 & 0.9785 & 1.0590 & 1.0258 \\
Sobral & 1.2006 & 1.0053 & 1.0909 & 1.1500 & 1.1565 \\
Uruburetama & 0.7135 & 0.7876 & 0.9045 & 1.0012 & 1.0263 \\
Várzea Alegre & 0.9381 & 0.8129 & 1.0064 & 1.1147 & 1.1582 \\
\hline
\end{tabular}

Fonte: Construída pelos autores a partir de dados dos Censos de 2000 e 2010.

Dados do IPECE (2012) apontam que o meio rural do estado do Ceará apresenta um menor grau de desigualdade de renda se comparado às áreas urbanas. Diante dessa evidência, rejeita-se a hipótese de Bourguignon (2002) em relação às microrregiões rurais do estado ${ }^{3}$, uma vez que a baixa eficiência do crescimento econômico na redução da pobreza ocorre principalmente no meio rural.

Mas, afinal, o que poderia explicar uma maior ocorrência de crescimento não pró-pobre em áreas rurais do Ceará? A explicação pode em parte estar na constatação de Resende et al. (2007), que, ao analisar a qualidade do crescimento econômico das capitais brasileiras, constataram que as regiões mais pobres se beneficiam menos com o crescimento econômico quando comparadas às regiões mais ricas. Sendo, portanto, o crescimento econômico pouco eficiente em reduzir a pobreza em regiões com maior incidência de pobreza inicial, como é o caso do meio rural cearense.

No Quadro 1 tem-se o resumo dos resultados produzidos pela pesquisa, separados por mesorregião. Observe que a mesorregião de melhor desempenho é a de Fortaleza, pois tanto a capital cearense quanto Pacajus apresentam crescimento pró-pobre na região como um todo. Ao analisar o Sul do estado, nota-se que apenas a Chapada do Araripe e Barro não apresentam crescimento em favor dos pobres. Já nos Sertões Cearenses, Crateús, Inhamuns, Quixeramobim e Senador Pompeu, não há nenhuma ocorrência de crescimento de natureza pró-pobre. O mesmo ocorre para o Centro Sul, em que Lavras da Mangabeira apresenta crescimento não pró-pobre e tanto em Várzea Alegre quanto Iguatu têm-se resultados inconclusivos. Nas demais regiões, Norte, Noroeste e Jaguaribe, tem-se crescimento pró-pobre para algumas microrregiões e crescimento não pró-pobre ou resultados inconclusivos para outras.

3 Em linhas gerais, a hipótese de Bourguignon (2002) prediz que, quanto mais desigual for a região, menor será a efetividade do crescimento econômico em reduzir a pobreza. 
Quadro1 - Resumo das Estimativas da Curva de Crescimento-Pobreza para as Áreas Rurais e Urbanas das Microrregiões Cearenses separadas por mesorregião.

\begin{tabular}{|c|c|c|c|}
\hline Sul & Geral & Urbana & Rural \\
\hline Barro & Pró-pobre & Não Pró-pobre & Inconclusivo \\
\hline Brejo Santo & Pró-pobre & Pró-pobre & Pró-pobre \\
\hline Cariri & Pró-pobre & Inconclusivo & Pró-pobre \\
\hline Caririaçu & Pró-pobre & Pró-pobre & Pró-pobre \\
\hline Chapada do Araripe & Pró-pobre & Inconclusivo & Inconclusivo \\
\hline Sertões Cearenses & Geral & Urbana & Rural \\
\hline Sertão de Crateús & Inconclusivo & Inconclusivo & Inconclusivo \\
\hline Sertão de Inhamuns & Pró-pobre & Inconclusivo & Inconclusivo \\
\hline Sertão de Quixeramobim & Inconclusivo & Não Pró-pobre & Inconclusivo \\
\hline Sertão de Senador Pompeu & Pró-pobre & Inconclusivo & Inconclusivo \\
\hline Jaguaribe & Geral & Urbana & Rural \\
\hline Baixo Jaguaribe & Pró-pobre & Inconclusivo & Pró-pobre \\
\hline Litoral de Aracati & Pró-pobre & Não Pró-pobre & Inconclusivo \\
\hline Médio Jaguaribe & Pró-pobre & Inconclusivo & Inconclusivo \\
\hline Serra do Pereiro & Pró-pobre & Inconclusivo & Inconclusivo \\
\hline Fortaleza & Geral & Urbana & Rural \\
\hline Fortaleza & Pró-pobre & Inconclusivo & Pró-pobre \\
\hline Pacajus & Pró-pobre & Não Pró-pobre & Pró-pobre \\
\hline Norte & Geral & Urbana & Rural \\
\hline Baixo Curu & Pró-pobre & Não Pró-pobre & Pró-pobre \\
\hline Baturité & Pró-pobre & Inconclusivo & Inconclusivo \\
\hline Canindé & Inconclusivo & Não Pró-pobre & Inconclusivo \\
\hline Chorozinho & Inconclusivo & Inconclusivo & Inconclusivo \\
\hline Itapipoca & Pró-pobre & Inconclusivo & Inconclusivo \\
\hline Médio Curu & Pró-pobre & Pró-pobre & Pró-pobre \\
\hline Cascavel & Pró-pobre & Inconclusivo & Pró-pobre \\
\hline Uruburetama & Inconclusivo & Não Pró-pobre & Inconclusivo \\
\hline Noroeste Cearense & Geral & Urbana & Rural \\
\hline Coreaú & Inconclusivo & Inconclusivo & Inconclusivo \\
\hline Ibiapaba & Pró-pobre & Inconclusivo & Pró-pobre \\
\hline Ipu & Inconclusivo & Inconclusivo & Inconclusivo \\
\hline Santa Quitéria & Inconclusivo & Não Pró-pobre & Pró-pobre \\
\hline Meruoca & Pró-pobre & Inconclusivo & Pró-pobre \\
\hline
\end{tabular}


(continuação)

\begin{tabular}{l|l|l|l}
\hline Noroeste Cearense & Geral & Urbana & Rural \\
\hline $\begin{array}{l}\text { Litoral de Camocim/Aca- } \\
\text { raú }\end{array}$ & Pró-pobre & Não Pró-pobre & Inconclusivo \\
Sobral & Pró-pobre & Inconclusivo & Pró-pobre \\
\hline Centro Sul & Geral & Urbana & Rural \\
\hline $\begin{array}{l}\text { Iguatu } \\
\text { Lavras da Mangabeira }\end{array}$ & Pró-pobre & Inconclusivo & Inconclusivo \\
Várzea Alegre & Inconclusivo & Não Pró-pobre & Não Pró-pobre \\
\hline
\end{tabular}

Fonte: Construída pelos autores a partir de dados dos Censos de 2000 e 2010.

As tabelas apresentadas nesta seção revelam, portanto, que a qualidade do crescimento econômico pode variar não somente dentro de uma mesma região, como também entre áreas urbanas e rurais, uma vez que se tem resultados de crescimento pró-pobre para o meio urbano da maioria das microrregiões e não pró-pobre para a maioria dessas microrregiões no meio rural.

Percebe-se também que, embora não tenha havido nenhuma modalidade de crescimento do tipo empobrecedor para as microrregiões cearenses, já que os valores para a Curva de crescimento-pobreza se mantiveram sempre positivos - com exceção de Crateús -, poucas são aquelas microrregiões em que a renda média dos percentis mais pobres da população cresce em uma proporção superior à renda dos mais ricos, resultando assim em um cenário de crescimento pró-pobre.

Os resultados obtidos nessa seção induzem a constatação de que a baixa capacidade do crescimento econômico do Ceará em promover a redução da pobreza em nível de microrregiões como um todo pode ser parcialmente explicada pela persistência de um modelo de crescimento econômico concentrador de renda. Ou seja, ainda que o crescimento promova certa redução da pobreza, a renda dos mais ricos cresce em uma proporção maior que a renda dos mais pobres.

\section{Considerações finais}

Este artigo analisou se o crescimento econômico no estado do Ceará, desagregado em nível microrregional, tem sido pró-pobre em suas áreas rurais e urbanas. Ou seja, se a renda dos pobres tem apresentado uma elevação superior ao verificado pela renda dos não pobres, induzindo, assim, uma redução na desigualdade. Nesse sentido, com base nos dados do Censo dos anos de 2000 e 2010, foram construídas as curvas de crescimento-pobreza, propostas por Son (2004).

Dentre os resultados obtidos constatou-se que apenas 14 das 33 microrregiões analisadas apresentam crescimento pró-pobre. Dentre essas microrregiões estão Fortaleza, 
Ibiapaba e Sobral. Ao separar as microrregiões por área urbana e rural, percebe-se que 23 do total de microrregiões apresentam crescimento em favor dos pobres em áreas urbanas (Baixo e Médio Jaguaribe, Fortaleza, Meruoca, Sobral etc.) e somente quatro experimentam essa modalidade de crescimento em áreas rurais (Brejo Santo, Caririaçu, Litoral de Aracati e Médio Curu). Esses resultados sugerem que o crescimento econômico é mais eficiente no combate à pobreza no meio urbano que no meio rural do estado.

Percebeu-se que a mesorregião de melhor desempenho é a de Fortaleza, pois tanto a capital cearense quanto Pacajus apresentam crescimento pró-pobre na região como um todo. No Sul do estado, apenas a Chapada do Araripe e Barro não apresentam crescimento em favor dos pobres. Já nos Sertões Cearenses, Crateús, Inhamuns, Quixeramobim e Senador Pompeu, não há ocorrência de crescimento pró-pobre. No Centro Sul, com exceção de Lavras da Mangabeira que apresenta crescimento não pró-pobre, tanto em Várzea Alegre quanto Iguatu têm-se resultados inconclusivos. As demais regiões apresentam crescimento pró-pobre para algumas microrregiões e crescimento não pró-pobre ou resultados inconclusivos para outras.

A baixa ocorrência de crescimento pró-pobre para as microrregiões como um todo induz a pressupor que o crescimento econômico do Ceará, em análise microrregional, segue a tendência de um modelo nordestino de crescimento concentrador de renda. $\mathrm{Ou}$ seja, ainda que este crescimento promova certa redução na pobreza, a renda dos mais ricos cresce em uma proporção maior que a renda dos mais pobres.

A partir dos resultados produzidos nessa pesquisa surge um importante questionamento: qual a natureza de um crescimento pró-pobre? Ou que modelo de crescimento resulta em benefícios para os pobres? Criar estratégias de políticas públicas capazes de estimular um crescimento econômico eficiente no combate à pobreza, principalmente no meio rural, poderia vir a ser um importante meio substitutivo de medidas paliativas de combate à pobreza como, por exemplo, o Programa Bolsa Família.

\title{
The effects of Economic Growth in Ceará Poverty: an analysis of microregions
}

\begin{abstract}
The paper analyzes the economic growth in the state of Ceará, broken down into microregional level, has been pro-poor in their urban and rural areas. It means, if the income of the poor has shown a higher elevation to the verified income the non-poor, thus inducing a reduction in inequality. In this sense, based on Census data from 2000 and 2010 are constructed curves of growth-poverty proposed by Son (2004). The results show that only 14 of the 33 microregions have been pro-poor growth. When the microregions are disaggregated into urban and rural areas, it appears that 23 microregions show growth in favor to the poor in urban areas and only four experience this kind of growth in rural areas. We notice then that economic growth of Ceará is ineffective in fighting poverty especially in rural areas.
\end{abstract}

Keywords: Pro-poor growth. Poverty. Inequality. 


\section{Referências}

AHLUWALIA, M. S.; CARTER, N. G.; CHENERY, H. B. Growth and Poverty in Developing Countries. Journal of Development Economics, v. 6, p. 299-341, 1979.

ASCHAUER, D. Is public expenditure productive? Journal of Monetary Economics, v. 23, p. 177-200, 1989.

ATKINSON, A. B. “On the Measurement of Poverty”, Econometrica, 55(4), 1987.

BARRETO, F. A. F. D. Crescimento econômico, pobreza e desigualdade: o que sabemos sobre eles? Série Ensaios Sobre Pobreza, n. 1, LEP/CAEN, Fortaleza, 2005.

BARRO, R. J. Government spending in a simple model of endogenous growth. The journal of Political Economy, v. 98, n. 5, p. 103-125, 1990.

. Economic growth in a cross-section of countries. The Quarterly Journal of Economics, v. 106, p. 407-444, 1991.

BARROS, R. P.; CARVALHO, M.; FRANCO, S. O Índice de Desenvolvimento da Família (IDF). Texto para discussão 986. Instituto de Pesquisa Econômica Aplicada - IPEA, 2003. BOURGUIGNON, F. The Growth Elasticity of Poverty Reduction: Explaining Heterogeneity across Countries and Time Periods. In: EICHER, T.; URNOVSKY, S. Inequality and Growth: Theory and Policy Implications. Cambridge: The MIT Press, 2002.

FOSU, A. K. Growth, Inequality, and Poverty Reduction in Developing Countries: Recent Global Evidence. UN University-World Institute for Development Economics Research (UNUWIDER). Version: September, 2010.

GUIDOLIN, S. M.; PORTO JÚNIOR, S. S. Expansão agrícola e crescimento econômico: impactos sobre a pobreza e a desigualdade. In: XI Encontro Regional de Economia do Nordeste, Fortaleza, 2006.

GONÇALVES, M. B. C.; SILVEIRA NETO, R. M. Crescimento pró-pobre nos municípios nordestinos: Evidências para o período de 1991-2000. Revista Econômica do Nordeste, v. 41, n. 3, 2010.

HOFFMAN, R. Distribuição de renda: medidas de desigualdade e pobreza. São Paulo: Editora da Universidade de São Paulo, 1998.

INSTITUTO BRASILEIRO DE GEOGRAFIA E ESTATÍSTICA - IBGE. Censo Demográfico 2010. Disponível em: <www.ibge.gov.br>. Acesso em: 2 jun. 2013.

. Distribuição dos pobres e desigualdade de renda no Brasil. Nota técnica, abril, 2012. Disponível em: <http://www.ibge.gov.br/>. Acesso em: 7 nov. 2013.

. Pesquisa Nacional de Amostra Por Domicílios. Nota técnica, junho, 2012. Disponível em: <http://www.sidra.ibge.gov.br/>. Acesso em: 6 nov. 2013.

INSTITUTO DE PESQUISA ECONÔMICA APLICADA - IPEA. Crescimento dos estados brasileiros. Nota técnica. Março, 2010. Disponível em: <http://www.ipea.gov.br/>. Acesso em: 3 jun. 2013. 
INSTITUTO DE PESQUISA E ESTRATÉGIA ECONÔMICA DO CEARÁ - IPECE. Sintese dos Principais Indicadores Social do Ceará. Fortaleza: IPECE, 2012. Disponível em: <http://www.ipece.ce.gov.br/>. Acesso em: 4 set. 2013.

INSTITUTO DE PESQUISA E ESTRATÉGIA ECONÔMICA DO CEARÁ IPECE IPECE. PIB cearense e seu desempenho setorial. Fortaleza: IPECE, 2012. Disponível em: <www.ipece.com.gov.br>. Acesso em: 15 dez. 2013.

KAKWANI, N.; KHANDKER, S.; SON, H. H. Pro-poor growth: concepts and measurement with country case studies. International poverty center, Working Paper n. 1, 2004. KAKWANI, N.; PERNIA, E. M. What is pro-poor growth? Asian Development Review, V. 18, n. 1, 2000.

KRAAY, A. When is growth pro-poor? cross-country evidence. International Monetary Fund (IMF), Working Paper n. 04/47, 2004.

MANSO, C. A.; PEREIRA, D. J. S. de. BARRETO, F. A. F. D. Crescimento pró-pobre: diferenças de intensidade entre o meio rural e urbano 2002-2005. Revista Econômica do Nordeste. Fortaleza, v. 39, n. 04, out/dez, 2008.

MARINHO, E. L; ARAÚJO, J. A. Crescimento Econômico e Concentração de Renda: seus efeitos na pobreza do Brasil. Série Working Paper BNDES/ANPEC, n. 24, 2012.

. Pobreza e o Sistema de Seguridade Social Rural no Brasil. Revista Brasileira de Economia, v. 64, n. 2, p. 161-174, 2010.

MARINHO, E.; SOARES, F. Impacto do crescimento econômico e da concentração de renda sobre a redução da pobreza nos estados brasileiros. In: Encontro Nacional de Economia XXXI, 2003. Porto Seguro. Porto Seguro: ANPEC, 2003.

MAYORGA, R. D.; TABOSA, F. J. S.; AMARAL FILHO, J. Análise de Desigualdade de Renda no Estado do Ceará. In: XLV Congresso da Sociedade Brasileira de Economia e Sociologia Rural, 2007, Brasília/DF. Conhecimentos para a Agricultura do Futuro. Brasília-DF: SOBER, 2007, v. 1. p. 1-17.

MORAIS, G. S; ARAÚJO, J. A.; MONTEIRO, V. B. Gastos Públicos e Crescimento Econômico: evidências da economia cearense. Encontro do Instituto de Pesquisa e Estratégia Econômica do Ceará, 2012. Fortaleza: IPECE, 2012.

PINTO, M. S.; OLIVEIRA, J. C. de. Crescimento pró-pobre: Análise dos estados brasileiros entre 1995 e 2007. Revista de Economia Contemporânea, Rio de Janeiro, v. 14, n. 2, maio/ago, 2010.

RAVALLION, M.; CHEN, S. Measuring pro-poor growth. World Bank Policy Research, Working Paper n. 2666, 2003, Washington.

. What can new survey data tell us about recent changes in distribution and poverty? World Bank Economic Review, v. 11, n. 2, p. 357-382, 1997.

RESENDE, G. M.; DA MATA, D.; CARVALHO, A. X. Y. Crescimento pró-pobre e distribuição de renda das capitais dos estados brasileiros. In: CARVALHO, A. X. Y.; OLIVEI- 
RA, C. W. A.; MOTA, J. A.; PIANCASTELLI, M. (orgs.). Ensaios de economia regional e urbana, IPEA, 2007.

ROCHA, S. Estimação de linhas de indigência e de pobreza: opções metodológicas no Brasil. In: HENRIQUES, Ricardo (org.). Desigualdade e pobreza no Brasil. RJ: IPEA, 2000. SALVATO, M. A. Crescimento pró-pobre no Brasil: uma avaliação empírica da década de 1990. Ensaios sobre pobreza, EP21, UFC, 2009.

SANTOS, R. C. L. O efeito do gasto público sobre o PIB dos municípios cearenses. Dissertação (Mestrado em Economia) UFC. Fortaleza, 2008.

SEN, A. Desigualdade reexaminada. Rio de Janeiro: Record, 2001. . Poverty: an ordinal approach to measurement. Econometrica, v. 44, 1976.

SILVEIRA NETO, R. Quão pró-pobre tem sido o crescimento econômico no Nordeste? Evidência para o período 1991-2000. In: Anais do X Encontro Regional de Economia, Fortaleza, 2005.

SON, H. H. A note on pro-poor growth. Economics Letters, n. 82, p. 307-304, 2004. STEWART, F. Distribuição de renda e desenvolvimento. Brasília: NEAD, 2000, 27p. TAQUES, F. H.; ROCHA, R. S. Oferta pública no combate à pobreza no Brasil: Uma análise a partir da curva crescimento-pobreza. In: Anais do XXXIX Encontro Nacional de Economia, Foz do Iguaçu, 2011.

TEJADA, C. A. O.; JACINTO, P. A.; DOS SANTOS, A. M. A. Pró-pobre ou empobrecedor: Qual a contribuição do crescimento econômico para Alagoas? In: Anais do XLVI Congresso da SOBER, Acre, 2008.

TOCHETTO, D. G.; RIBEIRO, E. P; COMIM, F. V.; PORTO JUNIOR, S. S. Crescimento pró-pobre no Brasil - uma análise exploratória. In: Anais do XXXII Encontro Nacional de Economia, 2004, João Pessoa.

UNDP - United Nations Development Program. Poverty Report, 2000.

Este trabalho foi financiado pela Fundação Cearense de Apoio ao Desenvolvimento Científico e Tecnológico - FUNCAP em parceria com o Conselho Nacional de Desenvolvimento Científico e Tecnológico CNPq.

Recebido para publicação em outubro de 2014. Aprovado para publicação em maio de 2015. 